In addition to the Ophthalmological Staff there are other departmental heads and assistants, totalling in all about forty instructors. This large corps of teachers enables the School to offer to the students a most comprehensive course in which the fundamentals of Ophthalmology as well as the relation of Ophthalmology to allied branches of medicine are largely emphasized.

\title{
The Registration of Sight-Testing Opticians
}

An interesting contribution to the perennial question of the registration of sight-testing opticians was made in the presidential address given by Dr. A. L. Kenny, of Melbourne, before the Section of Ophthalmology at the Australasian Medical Congress, recently held in Brisbane. The claims of opticians for Government registration are urged upon laymen, many of whom have obtained satisfactory reading glasses from opticians. They are accordingly in favour of the last-named. To argue before these men that opticians are not competent to test and to correct sight, because of their want of knowledge of the anatomy, physiology, and pathology of the eye, is to court an adverse verdict, since such of the opticians as have obtained the highest diplomas of the British Optical Association and similar bodies are in a position to produce sets of examination questions that would convince laymen that "such studies enter into the equipment of examination of candidates for these higher diplomas." The preliminary education and the training, general and special, of the candidates, it is true, cannot bear comparison with those of the medical student, if investigated by medical men, but under ordinary circumstances it would be impossible to persuade lay enquirers that the difference is so great as it really is. Dr. Kenny agrees that it is as impossible to prevent opticians from acting as sight-testers, as it is to suppress "counter prescribing" in the case of chemists. We must, however, never cease to oppose by all means in our power the Government of any State registering opticians as sight-testers, and in that way certifying to the public that these men are competent to test sight and to prescribe glasses. The fact that the bodies which issue diplomas to opticians forbid the use of drugs to paralyse accommodation, proves that the diplomâtes are not competent, for in many cases a test under cycloplegia shows a result different from that obtained by any subjective method of examination. Hence it is quite unjustifiable for any Government to certify to the public that a man who is forbidden by his diploma (and in the case of Queensland by the State law) to use cycloplegics is competent to test sight and to prescribe suitably. It is not 
suggested that the anatomy, physiology, and pathology demanded from the optician would satisfy the requirements of medical examiners, or that the number of opticians who possess that knowledge is large, but Dr. Kenny thinks that in this controversy we should meet and defeat the opticians on the highest plane. The general claim would then of necessity fail. Ophthalmologists in the State of Victoria have been able to induce various Governments to refrain from introducing a bill for sighttesting opticians. The opticians have recently prepared a draft bill and submitted it to the Committee of the Eye Section of the Victorian Branch of the British Medical Association by whom it has been carefully considered, and as a consequence a draft of the views of the Committee has been sent to the opticians. Among other suggestions is one " that sight-testing should not be referred to in the bill and should not form part of the curriculum." Dr. Kenny, however, evidently thinks this clause unworkable, and suggests that the way to meet the difficulty is for ophthalmologists to train themselves by special university and medical school courses to practise refraction work more thoroughly and more accurately than the most skilled "optologist" or "optometrist." "The public will soon recognize the higher class of work and the increased demand will call for an increased supply of highly-skilled ophthalmologists, which will in turn make void the contention of the opticians that the public must of necessity go to them, since there are not sufficient ophthalmologists to attend to them."

After Dr. Kenny had delivered his address, the Section agreed that it would assist the opticians in any efforts made to ensure a better education in their craft, but refused to have anything to do with the legal recognition of sight-testing on the part of people who had not received a medical education, a decision endorsed by the Congress as a whole.

\section{ABSTRACTS}

\section{I.-CATARACT EXTRACTION BY SUCTION}

(I) Barraquer y Barraquer, Ignacio (Barcelona). - A review of modern methods of cataract extraction. (Critique des méthodes modernes d'extraction de la cataracte.) La Clin. Ophtal., A pril, 1920.

(1) On page 580 of the British Journal of OphthalMOLOGY for 1918 will be found a short account in abstract of the suction method of removal of the lens in its capsule devised by 